\title{
Primary Language and Receipt of Recommended Health Care Among Hispanics in the United States
}

\author{
Eric $M$. Cheng, $M D, M S^{1,2,6}$, Alex Chen, $M D, M S^{3}$, and William Cunningham, $M D, M P H^{4,5}$ \\ 'Department of Neurology, VA Greater Los Angeles, Los Angeles, CA, USA; ${ }^{2}$ Department of Neurology, School of Medicine, University of \\ California Los Angeles, Los Angeles, CA, USA; ${ }^{3}$ Department of Pediatrics, University of Southern California, Los Angeles, CA, USA; ${ }^{4}$ Department \\ of Medicine, School of Medicine, University of California Los Angeles, Los Angeles, CA, USA; ${ }^{5}$ Department of Health Services, School of Public \\ Health, University of California Los Angeles, Los Angeles, CA, USA; 'VA Greater Los Angeles Healthcare System, Los Angeles, CA, USA.
}

BACKGROUND: Disparities in health care services between Hispanics and whites in the United States are well documented.

OBJECTIVE: The objective of the study was to determine whether language spoken at home identifies Hispanics at risk for not receiving recommended health care services.

DESIGN: The design of the study was cross-sectional, nationally representative survey of households.

PATIENTS: The patients were non-Hispanic white and Hispanic adults participating in the 2003 Medical Expenditure Panel Survey.

MEASUREMENTS: We compared receipt of ten recommended health care services by ethnicity and primary language adjusting for demographic and socioeconomic characteristics, health status, and access to care.

RESULTS: The sample included 12,706 whites and 5,500 Hispanics. In bivariate comparisons, $57.0 \%$ of whites received all eligible health care services compared to $53.6 \%$ for Hispanics who spoke English at home, 44.9\% for Hispanics who did not speak English at home but who were comfortable speaking English, and 35.0\% for Hispanics who did not speak English at home and were uncomfortable speaking English $(p<.001)$. In multivariate logistic models, compared to non-Hispanic whites, Hispanics who did not speak English at home were less likely to receive all eligible health care services, whether they were comfortable speaking English (risk ratio [RR] 0.88, 95\% confidence interval [CI] 0.74-0.97) or not (RR 0.84, 95\% CI 0.68-0.95).

CONCLUSIONS: Speaking a language other than English at home identified Hispanics at risk for not receiving recommended health care services, whether they were comfortable in speaking English or not. Identifying the mechanism for disparities by language usage may lead to interventions to reduce ethnic disparities.

KEY WORDS: disparities; Hispanic health; language barriers.

J Gen Intern Med 22(Suppl 2):283-8

DOI: $10.1007 / \mathrm{s} 11606-007-0346-6$

(C) Society of General Internal Medicine 2007

\section{INTRODUCTION}

According to recent census figures, Hispanics account for $14.1 \%$ of the U.S. population ${ }^{1}$. The most recent National Healthcare Disparities Report documented disparities in general health care access and quality between non-Hispanic whites and Hispanics in the United States ${ }^{2,3}$.

Disparities in health care affecting Hispanics may be attributable in part to language barriers. The National Healthcare Disparities Report described greater communication difficulties with health care providers among persons who did not speak English at home compared to English household speakers ${ }^{2}$. In addition, California residents with limited English proficiency had fewer health care visits than those with full English proficiency ${ }^{4}$.

In this study, we determined whether the language spoken at home identifies Hispanics at risk for not receiving ten recommended health care services using a nationally representative dataset of U.S. households.

\section{METHODS}

\section{Data Source, Sample}

We analyzed data from non-Hispanic white and Hispanic adults participating in the 2003 Medical Expenditure Panel Survey (MEPS), the most recent year that MEPS data were available when this study was undertaken. MEPS is supported by the Agency for Healthcare Research and Quality, and its design has been extensively described ${ }^{5}$. It is a nationally representative household survey of health care utilization in the United States noninstitutionalized civilian population. Data are collected during 5 face-to-face interviews with household representatives over a 2-year period. Data are collected for all members of a participating household. A new cohort is initiated every year. Minority and low-income households are oversampled to provide more precise estimates for these vulnerable populations. The 2003 MEPS collected data on 34,215 individuals living in 16,400 households and had a response rate for completing all interviews of $65 \%$.

More than 500 professionally trained interviewers collect data for MEPS. Interviewers recorded the language in which the interview was conducted. For the 2003 MEPS, interviewers used English for $84 \%$ of the sample, Spanish for $13 \%$ of the sample, both English and Spanish for 3\% of the sample, and a language other than English or Spanish for $0.002 \%$ of the sample. 


\section{Dependent Variable: Healthcare utilization}

Interviewers asked about receipt of the following 10 health care services:

$>$ Cancer screening: mammogram in the past 2 years for women over the age of 40 , pap smear in the past 3 years for women from age 18 to 65 who have not undergone a hysterectomy, and any history of colon cancer screening including fecal occult blood test, sigmoidoscopy, or colonoscopy for all persons over the age of 50

$>$ Cardiovascular disease prevention: blood pressure check in the past year, any history of cholesterol testing for men over the age of 35 and women over the age of 45 , smoking cessation advice in the past year for current smokers

$>$ Influenza vaccination in the past year for persons over the age of 65

$>$ Diabetes care among those who self-reported a diagnosis of diabetes: hemoglobin A1C check in the past year, foot exam in the past year, eye exam in the past 2 years.

Eligibility for these health care services was based on the recommendations from the U.S. Preventive Services Task Force and guidelines on diabetes care in existence in $2003^{6,7}$.

\section{Main Independent Variable}

Interviewers asked the household representative, "What language is spoken in your home most of the time?" If the answer was other than English, the interviewer asked, "Are all members of your household comfortable conversing in English?" If the answer was no, the interviewer asked, "Who is not comfortable conversing in English?"

Based on these questions, we defined 4 ethnic/English language usage groups. The first group was non-Hispanic whites who spoke English at home, the second group was Hispanics who spoke English at home, the third group was Hispanics who did not speak English at home but were comfortable speaking English, and the fourth group was Hispanics who did not speak English at home and were uncomfortable speaking English.

\section{Other Independent Variables}

Demographic and socioeconomic characteristics collected on our sample included self-reported ethnicity, age, sex, marital status, urban/rural status, highest level of education (did not finish high school, high school degree or equivalent, or education beyond high school), family income (less than $100 \%, 100 \%$ to less than $200 \%$, or greater than or equal to $200 \%$ of applicable poverty line), whether the person was born in the United States and if not, the number of years spent living in the United States (less than 5 years, 5-14 years, 15 or more years), self-reported health status (excellent/very good/ good versus fair/poor), and whether the person was the household representative answering questions for the interviewer (household representative versus proxy). Access to care characteristics included health insurance status (any private health insurance, Medicare but without private health insurance, Medicaid or other public health insurance but without private health insurance or Medicare, or uninsured) and having a usual source of care (provider usual source of care, facility usual source of care, or no usual source of care).

\section{Analysis}

Bivariate analyses were performed relating ethnicity/English language usage with other independent variables and receipt of recommended health care services for which the person was eligible. Multivariate logistic regression models were constructed for each of the 10 health care services, adjusting for ethnicity/English language use and all other independent variables described above. To summarize findings of these 10 models, we also constructed models for receipt of all eligible health care services in categories of cancer screening, cardiovascular disease prevention, influenza vaccination, diabetes care, and across all categories as an "all-or-none" measure ${ }^{8}$. In other words, persons were categorized as receiving all eligible services versus not receiving all eligible services.

We used the regression coefficients derived from the multivariate logistic regression models to predict the adjusted probabilities of receiving health care services after first assigning every person in the sample to the non-Hispanic white group, then assigning the sample to the other Hispanic/ English language usage groups, leaving the other independent variables at their original values. Risk ratios (RRs) of receiving health care services by ethnicity/English language usage were calculated by dividing predicted probabilities. Confidence intervals (CIs) for RRs were obtained through 500 iterations of a bootstrapping technique ${ }^{9}$.

We performed a sensitivity analysis on the impact of the proxy-report on our findings by including only data from persons who reported on their own health care (self-report) and excluding health care data that were reported by another person (proxy-report). We also performed a second sensitivity analysis that excluded all persons without health insurance.

Analyses were conducted using Stata, Version 8.2 (College Station, TX). All results accounted for clustering by household and were weighted to account for nonrespondents and oversampling of minorities and low-income households to give estimates of the U.S. civilian noninstitutionalized population. Approval of this project was obtained from the VA Greater Los Angeles Healthcare System Institutional Review Board.

\section{RESULTS}

Of the 12,971 non-Hispanic white adults, the overwhelming majority $(12,706$, weighted percentage $98.1 \%)$ spoke English at home; for the analyses reported here, we dropped the remaining 265 non-Hispanic whites who did not speak English at home. Of the 5,500 Hispanics, 1,977 (weighted percentage 43.9\%) spoke English at home, 1,697 (weighted percentage $30.5 \%$ ) did not speak English at home but were comfortable speaking English, and 1,826 (weighted percentage 25.6\%) did not speak English at home and were uncomfortable speaking English. Accounting for population weights, our sample represents 148.5 million non-Hispanic white adults who speak English at home, 11.7 million Hispanic adults who speak English at home, 8.1 million Hispanic adults who do not speak English at home but are comfortable speaking English, and 6.8 million Hispanic adults who do not speak English at home and are uncomfortable speaking English.

There was a gradient among ethnicity/English language usage groups, in terms of characteristics associated with health care utilization, with non-Hispanic whites being least 
disadvantaged and Hispanics who were uncomfortable speaking English being most disadvantaged (Table 1). Some highlighted characteristics for the latter group include lower levels of education, lower family income, lack of insurance, and lack of usual source of care $(p<.001)$.
Overall, $55 \%$ of our sample received all recommended health care services for which they were eligible. Again, there were significant differences in receipt of recommended health care services along ethnicity/English language usage groups with the exception of diabetes management (Table 1). Non-Hispanic

Table 1. Characteristics of the U.S. Civilian Population, by Ethnicity/English Language Usage

\begin{tabular}{|c|c|c|c|c|}
\hline & \multirow{3}{*}{$\begin{array}{l}\text { Non-Hispanic white, English } \\
\text { spoken at home, } n=12,706\end{array}$} & \multicolumn{3}{|l|}{ Hispanic, $n=5,500$} \\
\hline & & \multirow{2}{*}{$\begin{array}{l}\text { English spoken at } \\
\text { home } n=1,977\end{array}$} & \multicolumn{2}{|c|}{ English not spoken at home, $n=3,523$} \\
\hline & & & $\begin{array}{l}\text { Comfortable speaking } \\
\text { English } n=1,697\end{array}$ & $\begin{array}{l}\text { Not comfortable speaking } \\
\text { English } n=1,826\end{array}$ \\
\hline Age (years) & 47.5 & 38.9 & 36.8 & 41.0 \\
\hline Female (\%) & 51.8 & 50.7 & 43.2 & 51.7 \\
\hline Currently married (\%) & 58.4 & 47.9 & 50.8 & 61.1 \\
\hline Rural status (\%) & 22.4 & 9.1 & 7.8 & 8.7 \\
\hline \multicolumn{5}{|l|}{ Education (\%) } \\
\hline Beyond high school & 35.4 & 21.8 & 13.2 & 4.2 \\
\hline High school degree or equivalent & 51.9 & 51.6 & 42.7 & 19.8 \\
\hline Did not finish high school & 12.4 & 26.4 & 43.8 & 75.9 \\
\hline \multicolumn{5}{|l|}{ Family income (\%) } \\
\hline$\geq 200 \%$ of poverty & 77.8 & 67.0 & 50.6 & 30.5 \\
\hline 100 to $199 \%$ of poverty & 14.2 & 19.0 & 32.6 & 39.9 \\
\hline$<100 \%$ of poverty & 8.0 & 14.1 & 16.8 & 29.6 \\
\hline \multicolumn{5}{|l|}{$\begin{array}{l}\text { Country of origin/years in the } \\
\text { United States }(\%)\end{array}$} \\
\hline Born in the United States & 96.2 & 74.8 & 27.4 & 5.5 \\
\hline Immigrated less than 5 years ago & 0.3 & 0.3 & 7.3 & 20.8 \\
\hline Immigrated 5 to 14 years ago & 0.5 & 5.2 & 26.5 & 39.9 \\
\hline Immigrated 15 or more years ago & 3.0 & 19.7 & 38.2 & 33.7 \\
\hline Fair/poor health status (\%) & 12.1 & 13.0 & 12.5 & 17.3 \\
\hline $\begin{array}{l}\text { Self-response of household } \\
\text { representative (vs proxy; \%) }\end{array}$ & 60.3 & 58.2 & 46.5 & 50.6 \\
\hline \multicolumn{5}{|l|}{ Health insurance (\%) } \\
\hline Private insurance & 79.2 & 65.3 & 46.2 & 25.5 \\
\hline Medicare & 7.9 & 6.3 & 6.0 & 10.3 \\
\hline Medicaid & 3.4 & 9.2 & 10.3 & 12.0 \\
\hline Uninsured & 9.5 & 19.3 & 37.4 & 52.2 \\
\hline \multicolumn{5}{|l|}{ Usual source of care (\%) } \\
\hline Provider & 44.6 & 34.8 & 22.8 & 15.6 \\
\hline Facility & 37.6 & 34.2 & 31.0 & 28.8 \\
\hline None & 17.8 & 31.0 & 46.3 & 55.6 \\
\hline \multicolumn{5}{|l|}{ Healthcare utilization (\%) } \\
\hline Mammogram $(n=5,511)$ & 74.5 & 71.1 & 70.3 & 58.6 \\
\hline Pap smear $(n=5,999)$ & 89.7 & 89.2 & 83.8 & 84.3 \\
\hline $\begin{array}{l}\text { Colorectal cancer screening } \\
(n=6,629)\end{array}$ & 62.7 & 49.9 & 26.6 & 26.7 \\
\hline $\begin{array}{l}\text { Summary: Cancer screening } \\
(n=11,574)\end{array}$ & 66.4 & 67.4 & 56.8 & 54.2 \\
\hline Blood pressure check $(n=17,636)$ & 83.4 & 75.9 & 64.3 & 57.1 \\
\hline Cholesterol check $(n=9,754)$ & 92.9 & 88.4 & 80.5 & 76.1 \\
\hline $\begin{array}{l}\text { Smoking cessation advice } \\
(n=2,901)\end{array}$ & 59.8 & 49.0 & 42.0 & 52.5 \\
\hline $\begin{array}{l}\text { Summary: CV disease prevention } \\
(n=17,761)\end{array}$ & 76.5 & 69.4 & 59.3 & 52.8 \\
\hline $\begin{array}{l}\text { Summary: Influenza vaccination } \\
(n=2,888)\end{array}$ & 74.4 & 70.3 & 52.7 & 50.0 \\
\hline $\begin{array}{l}\text { HbAlc check among diabetics } \\
(n=868)\end{array}$ & 91.0 & 89.5 & 85.7 & 83.6 \\
\hline $\begin{array}{l}\text { Foot exam among diabetics } \\
(n=1,061)\end{array}$ & 72.3 & 72.2 & 59.5 & 73.4 \\
\hline $\begin{array}{l}\text { Eye exam among diabetics } \\
(n=1,091)\end{array}$ & 68.3 & 60.6 & 56.0 & 59.9 \\
\hline $\begin{array}{l}\text { Summary: Diabetes management } \\
(n=851)\end{array}$ & 54.0 & 47.0 & 41.7 & 44.5 \\
\hline $\begin{array}{l}\text { Summary: All eligible health care } \\
\text { services }(n=17,820)\end{array}$ & 57.0 & 53.6 & 44.9 & 35.0 \\
\hline
\end{tabular}

All results weighted to give estimates of the U.S. civilian noninstitutionalized population CV Cardiovascular

${ }^{*} p<.001$ across 4 ethnicity/English language usage categories by chi-squared or $t$ tests 
Table 2. Multivariate Logistic Regression Model for Receipt of All Eligible Health Care Services

\begin{tabular}{|c|c|}
\hline $\begin{array}{l}\text { Receipt of all health care services for } \\
\text { which a person is eligible }\end{array}$ & $\begin{array}{l}\text { Odds ratio } \\
(95 \% \mathrm{Cl})\end{array}$ \\
\hline \multicolumn{2}{|l|}{ Ethnicity/language usage } \\
\hline $\begin{array}{l}\text { Non-Hispanic white, English spoken } \\
\text { at home }\end{array}$ & - \\
\hline Hispanic, English spoken at home & $\begin{array}{l}0.89(0.77 \\
\text { to } 1.03)\end{array}$ \\
\hline $\begin{array}{l}\text { Hispanic, English not spoken at home, } \\
\text { comfortable with English }\end{array}$ & $\begin{array}{c}0.77(0.63 \\
\text { to } 0.94)\end{array}$ \\
\hline Hispanic, not comfortable with English & $\begin{array}{c}0.70(0.55 \\
\text { to } 0.89)\end{array}$ \\
\hline Age (years) & $\begin{array}{c}0.98(0.97 \\
\text { to } 0.98)\end{array}$ \\
\hline Female & $\begin{array}{c}1.12(1.04 \\
\text { to } 1.22)\end{array}$ \\
\hline Currently not married & $\begin{array}{l}0.76(0.70 \\
\text { to } 0.83)\end{array}$ \\
\hline Rural & $\begin{array}{c}0.82(0.75 \\
\text { to } 0.91)\end{array}$ \\
\hline \multicolumn{2}{|l|}{ Highest level of education } \\
\hline Beyond high school & - \\
\hline High school degree or equivalent & $\begin{array}{l}0.94(0.85 \\
\text { to } 1.04)\end{array}$ \\
\hline Did not finish high school & $\begin{array}{c}0.73(0.64 \\
\text { to } 0.84)\end{array}$ \\
\hline \multicolumn{2}{|l|}{ Family Income } \\
\hline$\geq 200 \%$ poverty & - \\
\hline $100 \%$ to $199 \%$ poverty & $\begin{array}{c}0.76(0.68 \\
\text { to } 0.85)\end{array}$ \\
\hline$<100 \%$ poverty & $\begin{array}{c}0.76(0.66 \\
\text { to } 0.87)\end{array}$ \\
\hline \multicolumn{2}{|l|}{ US born/time spent in United States } \\
\hline US born & - \\
\hline Immigrated less than 5 years ago & $\begin{array}{l}1.11(0.76 \\
\text { to } 1.63)\end{array}$ \\
\hline Immigrated 5 to 14 years ago & $\begin{array}{l}1.39(1.09 \\
\text { to } 1.78)\end{array}$ \\
\hline Immigrated 15 or more years ago & $\begin{array}{l}1.07(0.90 \\
\text { to } 1.27)\end{array}$ \\
\hline Fair/poor health status & $\begin{array}{l}1.07(0.95 \\
\text { to } 1.21)\end{array}$ \\
\hline Proxy respondent & $\begin{array}{l}0.77(0.71 \\
\text { to } 0.83)\end{array}$ \\
\hline \multicolumn{2}{|l|}{ Health insurance } \\
\hline Private insurance & - \\
\hline Medicaid & $\begin{array}{l}0.88(0.75 \\
\text { to } 1.04)\end{array}$ \\
\hline Medicare & $\begin{array}{l}1.00(0.85 \\
\text { to } 1.18)\end{array}$ \\
\hline Uninsured & $\begin{array}{l}0.44(0.38 \\
\text { to } 0.50)\end{array}$ \\
\hline \multicolumn{2}{|l|}{ Usual source of care } \\
\hline Provider & - \\
\hline Facility & $\begin{array}{l}1.00(0.92 \\
\text { to } 1.10)\end{array}$ \\
\hline None & $\begin{array}{l}0.42(0.37 \\
\text { to } 0.47)\end{array}$ \\
\hline
\end{tabular}

All results in bold signify $p \leq 0.01$

whites were most likely to receive eligible care, followed by Hispanics who spoke English at home, then Hispanics who did not speak English at home but were comfortable speaking English, and finally Hispanics who were uncomfortable speaking English. The unadjusted disparity in receipt of all recommended health care between non-Hispanic whites and Hispanics who were uncomfortable speaking English was $22.0 \%$ (57.0 versus $35.0 \%$, respectively, $p<.001$ ).
In the multivariate logistic models, the following characteristics were associated with not receiving all recommended health care services: Hispanics who did not speak English at home, whether they were comfortable speaking English or not (compared to non-Hispanic whites), older age, male, not currently married, rural status, not finishing high school, having family income below $200 \%$ of applicable poverty line, proxy response, not having any health insurance, and not having any usual source of care $(p<.05$, Table 2$)$.

The predicted probabilities based on the multivariate logistic models of receiving recommended health care services by ethnicity/English language usage groups are presented in Table 3. Ethnicity/English language usage variables were no longer independently associated with the receipt of the 4 categories of health care services with the exception of cancer screening. In the receipt of all eligible health care services, there was no significant difference between non-Hispanic whites and Hispanics who spoke English at home (RR 0.96, 95\% CI 0.87-1.01). However, compared to non-Hispanic whites, Hispanics who did not speak English at home were less likely to receive all eligible services, whether they were comfortable speaking English (RR 0.89, 95\% CI 0.75-0.97) or uncomfortable speaking English (RR 0.85, 95\% CI 0.69-0.95). In the adjusted models, the disparity in receipt of all recommended health care services between non-Hispanic whites and Hispanics who were uncomfortable speaking English was 7.6\% (56. 1 versus $48.5 \%$, respectively).

Of the 18,206 persons in our sample, $10,153(56 \%)$ were based on self-report and 8,053 (44\%) were based on a response by someone else in the household (proxy-response). After eliminating all proxy responses, the disparities in the receipt of all eligible health care services were smaller but still substantial in unadjusted analyses (non-Hispanic whites 58.3\%, Hispanics who spoke English at home 56.9\%, Hispanics who did not speak English at home but were comfortable speaking English 50.3\%, Hispanics who were uncomfortable speaking English $43.9 \%, p<.001$ by chi-squared tests). However, after adjustment in multivariate logistic models, the ethnicity/language groups were no longer significantly different. In a second sensitivity analysis, after dropping 3,644 persons without insurance, the results remained unchanged from the original analysis: Insured Hispanics who did not speak English at home were less likely than insured whites to receive all eligible recommended services, whether they were comfortable speaking English (RR 0.87 95\% CI 0.73-0.97) or not (RR 0.79, 95\% CI 0.62-0.92).

\section{DISCUSSION}

Our findings show that Hispanics who speak English at home receive recommended health care services in similar proportions to non-Hispanic whites. However, speaking a language other than English at home identified a group of Hispanics at risk for not receiving recommended health care services, whether they were comfortable speaking English or not. These disparities were clearly seen in the unadjusted comparisons and persisted after adjusting for other characteristics related to health care utilization.

Although non-English speakers in the United States have repeatedly reported lower satisfaction with and access to care ${ }^{2,4,10}$, there is less information on receipt of health care 
Table 3. Receipt of Eligible Health Services, by Ethnicity/English Language Usage

\begin{tabular}{lll}
\hline $\begin{array}{l}\text { Model predicting use of all } \\
\text { eligible preventive services }\end{array}$ & $\begin{array}{l}\text { Adjusted } \\
\text { probability }\end{array}$ & $\begin{array}{l}\text { Relative risk compared } \\
\text { to non-Hispanic white } \\
(95 \% \mathrm{Cl})\end{array}$
\end{tabular}

Cancer screening

Non-Hispanic white,

English spoken at home

Hispanic, English spoken at home

Hispanic, English not spoken at home AND Comfortable with English Not comfortable with English

Cardiovascular disease

prevention

Non-Hispanic white,

English spoken at home

Hispanic, English spoken

at home

Hispanic, English not

spoken at home AND

Comfortable with English

Not comfortable with

English

Influenza vaccination

Non-Hispanic white,

English spoken at home

Hispanic, English spoken

at home

Hispanic, English not

spoken at home AND

Comfortable with English

Not comfortable with

English

Diabetes management

Non-Hispanic white,

English spoken at home

Hispanic, English spoken

at home

Hispanic, English not

spoken at home AND

Comfortable with English

Not comfortable with

English

66.4

64.5

0.97 (0.87 to 1.04$)$

57.7

60.1

0.86 (0.68 to 0.97$)$

0.90 (0.72 to 1.01$)$

74.6

75.7

$1.02(0.98$ to 1.11$)$

73.8

70.5

0.99 (0.89 to 1.07$)$

0.94 (0.77 to 1.01 )

73.7

74.5

$1.01(0.87$ to 1.17$)$

65.4

65.0

0.88 (0.60 to 1.07$)$

0.88 (0.62 to 1.05$)$

52.9

$1.02(0.74$ to 1.38$)$

48.7

55.9

$0.91(0.54$ to 1.45$)$

1.06 (0.62 to 1.67 )

All eligible preventive

services

Non-Hispanic white,

English spoken at home

Hispanic, English spoken at home

Hispanic, English not

spoken at home

Comfortable with English

Not comfortable with

English

Models adjust for age, sex, marital status, urban/rural, education, family income, country of origin/years in the United States, self-reported health status, proxy response, health insurance, and usual source of care.

All results in bold signify $p<0.05$

services by household language. Most studies focus only on screening for gynecological cancer ${ }^{11-16}$. Of other research studies on language barriers and health care services, only 1 included as many non-English speakers ${ }^{17}$, none were a nationally representative sample, and none analyzed as many health care services as the current study. Nevertheless, our findings are consistent with the literature that show lower rates of health care screening services among non-English speakers in the United States, Canada, and the UK ${ }^{11-20}$.
There are at least 3 mechanisms by which English language usage may be associated with disparities in health care utilization ${ }^{12}$. For receipt of all recommended health care services, adjustment for characteristics related to health care utilization reduced the magnitude of disparities associated with language usage by about two thirds. Adjustment for additional omitted variables may have reduced the disparities by language usage even further; that is, it is possible that the observed differences were not attributable to language per se but rather to residual confounding by other factors associated with primary language (e.g., degree of poverty, quality of health insurance coverage). However, it is also possible that these factors are not confounders of the association between primary language and health care utilization but rather part of the causal pathway. For instance, it is possible that language barriers are directly responsible for limited incomeproducing opportunities or for difficulties finding a usual source of care. In this case, adjusting for income and usual source of care underestimates the true impact of language barriers on health care utilization.

Second, difficulties with using English may be responsible for communication difficulties with health care providers. Interventions that increase access to interpreters and bilingual health care providers would be expected to reduce disparities caused by this mechanism ${ }^{21}$. However, we note that in our study, Hispanics who were comfortable speaking Englishalthough they spoke another language at home-were less likely to receive health care services compared to non-Hispanic whites in both unadjusted and adjusted analyses, implying that communication difficulties are not likely to be the only mechanism explaining disparities by language usage.

A third mechanism is that English language usage is a marker of health care-seeking behavior. Persons with greater English language usage are likely to be more acclimated to the dominant culture in the United States and thus may adopt the health careseeking behaviors of the mainstream population. For example, we observed large disparities in influenza vaccination by language usage. Racial differences in influenza vaccination are probably not completely explained by differences in access to care, as most persons eligible for influenza vaccination have Medicare insurance ${ }^{22}$. Instead, influenza vaccination uptake may be influenced by beliefs such as the likelihood of getting sick from the vaccination or by attitudes such as trust in the medical system ${ }^{23}$. Therefore, educational activities about health carescreening services delivered to communities with high proportions of non-English speakers may be necessary to reduce disparities ${ }^{14}$. Limited English language usage may also be a marker of lack of documentation, which may be associated with a reluctance to seek health care because of fear of deportation ${ }^{24,25}$.

In general, we did not find statistical differences between ethnicity/language groups within categories of health care services in our multivariate models; only when an overall "all-or-none" measurement was used as our dependent variable were disparities apparent between non-Hispanic whites and Hispanics who did not speak English at home. Advocates of "allor-none" measurement argue that it is the best approach because it promotes the ideal of optimal care, reflects the interests of patients and the performance of the health care system as a whole, and is sensitive to changes in performance ${ }^{8}$.

The following limitations to our study should be noted. Receipt of health services was based on self-report and was not independently documented. Second, there are sparse data on 
how our constructed variable of English language usage compares to other variables of English usage not available in MEPS, such as self-reported English proficiency levels. One study showed that language proficiency may be a more sensitive measure in identifying vulnerable populations than household language ${ }^{4}$. Third, English language usage is necessary for but not equivalent to health literacy, a potential barrier not measured among our sample.

Our findings are particularly important given the rapid growth of the Hispanic population in the United States. Identifying Hispanics at highest risk for not receiving recommended health care services is crucial so that health care providers and policy makers can design and implement interventions to reduce disparities in health care.

Acknowledgments: The project described was supported by UCLA/ DREW Project EXPORT, NCMHD, P2OMD000148/P2OMDOOO182 from NCMHD, and its contents are solely the responsibility of the authors and do not necessarily represent the official views of the NCMHD. Stefanie Vassar, MS, retrieved and formatted data for analysis for this study. We thank Robert Brook, $M D, S c D$ for reviewing a draft of this manuscript.

Conflict of interest: None disclosed.

Corresponding Author: Eric M. Cheng, MD, MS; VA Greater Los Angeles Healthcare System, 11301 Wilshire Blvd., B500, ML 127, Los Angeles, CA 90073, USA (e-mail: eric.cheng@va.gov).

\section{REFERENCES}

1. Long JS. Regression Models for Categorical and Limited Dependent Variables. Thousand Oaks, CA: Sage; 1997

2. Agency for Healthcare Research and Quality National Healthcare Disparities Report. Report no. 06-0017. Rockville, MD: Agency for Healthcare Research and Quality.

3. Kelley E, Moy E, Stryer D, Burstin H, Clancy C. The national healthcare quality and disparities reports: an overview. Med Care. 2005; 43:I3-18, Mar.

4. Ponce NA, Hays RD, Cunningham WE. Linguistic disparities in health care access and health status among older adults. J Gen Intern Med. 2006; 21:786-791, Jul.

5. Cohen SB. Design strategies and innovations in the medical expenditure panel survey. Med Care. 2003; 41:III5-III12, Jul.

6. U.S. Preventive Services Task Force. (cited 2006 August 10); Available from: http://www.ahrq.gov/clinic/uspstfix.htm
7. American Diabetes Association. Standards of medical care for patients with diabetes mellitus. Diabetes Care. 2003; 26:33S- 50S, Jan 1.

8. Nolan T, Berwick DM. All-or-none measurement raises the bar on performance. JAMA. 2006; 295:1168-1170, Mar 8.

9. Efron B, Tibshirani RJ. An Introduction to the Bootstrap. New York, NY: Chapman and Hall; 1993

10. Morales LS, Cunningham WE, Brown JA, Liu H, Hays RD. Are Latinos less satisfied with communication by health care providers? J Gen Intern Med. 1999; 14:409-417, Jul.

11. Jacobs EA, Karavolos K, Rathouz PJ, Ferris TG, Powell LH. Limited english proficiency and breast and cervical cancer screening in a multiethnic population. Am J Public Health. 2005; 95:1410-1416, Aug.

12. Woloshin S, Schwartz LM, Katz SJ, Welch HG. Is language a barrier to the use of preventive services? J Gen Intern Med. 1997; 12:472-477, Aug.

13. Stein JA, Fox SA. Language preference as an indicator of mammography use among Hispanic women. J Natl Cancer Inst. 1990; 82:1715-1716, Nov.

14. Naish J, Brown J, Denton B. Intercultural consultations: investigation of factors that deter non-English speaking women from attending their general practitioners for cervical screening. BMJ. 1994; 309:1126-1128, Oct 29.

15. Harlan LC, Bernstein AB, Kessler LG. Cervical cancer screening: who is not screened and why? Am J Public Health. 1991; 81:885-890, Jul

16. Marks G, Solis J, Richardson JL, Collins LM, Birba L, Hisserich JC. Health behavior of elderly Hispanic women: does cultural assimilation make a difference? Am J Public Health. 1987; 77:1315-1319, Oct

17. Solis JM, Marks G, Garcia M, Shelton D. Acculturation, access to care, and use of preventive services by Hispanics: findings from HHANES 1982-84. Am J Public Health. 1990 80Suppl:11-19, Dec.

18. LiaoXH, Mcllwaine G. The health status and health needs of Chinese population in Glasgow. Scott Med J. 1995; 40:77-80, Jun.

19. Hu DJ, Covell RM. Health care usage by Hispanic outpatients as function of primary language. West J Med. 1986; 144:490-493, Apr.

20. Jacobs E, Chen AH, Karliner LS, Agger-Gupta N, Mutha S. The need for more research on language barriers in health care: a proposed research agenda. Milbank Q. 2006; 84:111-133

21. Brach C, Fraser I, Paez K. Crossing the language chasm. Health Aff (Millwood). 2005; 24:424-434, Mar-Apr.

22. Hebert PL, Frick KD, Kane RL, McBean AM. The causes of racial and ethnic differences in influenza vaccination rates among elderly Medicare beneficiaries. Health Serv Res. 2005; 40: 517-37, Apr.

23. Winston CA, Wortley PM, Lees KA. Factors associated with vaccination of medicare beneficiaries in five U.S. communities: Results from the racial and ethnic adult disparities in immunization initiative survey, 2003. J Am Geriatr Soc. 2006; 54:303-310, Feb.

24. Bauer HM, Rodriguez MA, Quiroga SS, Flores-Ortiz YG. Barriers to health care for abused Latina and Asian immigrant women. J Health Care Poor Underserved. 2000; 11:33-44, Feb.

25. Garces IC, Scarinci IC, Harrison L. An examination of sociocultural factors associated with health and health care seeking among Latina immigrants. J Immigr Minor Health. 2006; 83:77-85, Oct. 